\title{
Reconstruction and Adjustment of Economic Law Based on Ecological Civilization Construction Theory
}

\author{
Yongping Zhang \\ Langfang Normal University, Langfang, 065000, China
}

Keywords: Ecological civilization construction. Economic law. Reconstruction and adjustment

\begin{abstract}
Ecological civilization is a type of advanced civilization form, important symbol of human beings bidding farewell to barbarism and ignorance, important result of human beings cognizing world and reforming world and also significant symbol of continuous development and progress of human society. In current situation, China proposes that construction of socialist ecological civilization is an important mode to promote long-term stable and sustainable development of society and economy. This move becomes a new opportunity for reconstruction and adjustment of China's economy law. Ecological civilization construction has close relation with economic law. To deal with well the relationship between the two, the contradictions between economic law and ecological civilization construction must be solved. It is required to adjust and reconstruct economic law under the theory of ecological civilization construction, guarantee ecological civilization construction with economic law and promote perfection of economic law with the idea of ecological civilization.
\end{abstract}

\section{Foreword}

Civilization development degree is social development degree. "Ecological civilization is the sum of material achievements and spiritual achievements gained by human through following harmonious development of human, nature and society; it refers to cultural ethic form with the basic aim of harmonious coexistence, virtuous circle, virtuous circle and continuous prosperity of human \& nature, humans and human \& society”. It reflects comprehensive developmental level of a country. It is the sum of material achievements and spiritual achievements formed on the basis of following harmonious development of human, nature and society. The representations are as follows: establish awareness of ecological balance and environmental protection; set up perfect economic operation order; establish perfect social security system; harmonious and sustainable development of society. Ecological civilization is basically reflected in new social development status of harmonious coexistence, joint development and continuous prosperity of society, human and nature. It should contain two layers: 1) civilization formed in the process of reformation of the world by human through following natural ecological law (dependence relationship and living status among bionts except human and between bionts and environment); 2) civilization formed by humanized nature in the process where human beings reform the world, change the law of natural ecology and incorporate natural ecology in practice. It is a harmonious way sought by subjectivity acting on objectivity. In the two layers, the latter is a more complex, comprehensive, advanced and balanced state and also a higher layer of ecological civilization development.

\section{Inner relation between economic law and ecological civilization construction}

Economic law serves social and economic development, provides operation rules of sociality and economy and ensures balanced and stable development of society and economy. Ecological civilization construction pays attention to operation status of the whole society, stresses joint development of material civilization, spiritual civilization and ecological civilization. Economic law as the basic guarantee for joint development of the three has interactive and stimulative inner relation with ecological civilization construction, which is mainly reflected in the following aspects:

Firstly, economic law and ecological civilization construction are inevitable products of social development. Productivity development is the foundation of social progress. Economic development 
is the driving force of social development. As economic development level improves continuously, economic operation also should own more effective management rules. At present, market economy is the development mainstream. Economic operation keeps certain liberalization. Since economic benefit and social benefit have some contradictions, free operation mode may not meet social development needs. Thus, the government needs to utilize related laws and regulations for standardization. Similar to economic law, the principle of sustainable development is also an idea of changing traditional development mode. It is put forward after sociality and economy develop to some extent and human begins realize human and nature should harmoniously coexist and develop jointly. It is an important move to improve ecological environment and guarantee sustainable development of human beings.

Secondly, economic law and ecological civilization construction have common development goals. Economic law is the foundation of social and legal systems. Its purpose is to ensure good social operation state. Economic law is formulated according to objective laws of social and economic development in order to ensure circulation of economic interest and social development balance, form optimized resource allocation and sustainable development mode. Besides, fairness is the objective pursued by laws. About this point economic law and ecological civilization construction have commonality. The common development goal makes economic law and ecological civilization construction reach a balance in the process of scoail development.

Thirdly, economic law and ecological civilization construction have the same functions for social development. Economic law is a means to intervene market economic operation with the law. It is used to overcome some defects of market economy, minimize hazards and ensure normal economic operation and stable life. The effects of ecological civilization construction are the same. Under the condition of creating conditions for development, it is required to cope with well the relationship between economic development and ecological environment and guarantee sustainable development of human society.

Fourthly, economic law is significant guarantee of successful construction of socialist ecological civilization. Ecological civilization construction is the ideal direction of China's national construction. From the perspective of sustainable development, social development mode of joint development of economic benefit, ecological benefit and social benefit is the main developing route. Legal adjustment is the main means for the government to achieve this objective. So, it is required to change traditional ideas, adjust and control economic development mode from the perspective of economic law, regard intensive social construction as the objective, reduce environmental damage in economic development process, implement scientific development perspective and accelerate construction of harmonious socialist society. It can be seen from this point that socialist ecological civilization construction and economic law have the relationship of mutual promotion and joint development. Economic law can create good conditions for sustainable development and ecological civilization construction. In the society with ecological civilization, the idea of economic law legislation will be further reformed. The contents will be richer and can better satisfy the need of social sustainable development.

\section{Traditional idea and adjustment of Chinese economic law}

Since China established the system of socialist law, Chinese economic law has experienced time text, continuously accumulated experience in development of socialist market economy and formed socialist economic legal system with Chinese characteristics. This legal system provides many aspects related to operation of market economy. Generally, these aspects can be summarized as follows: ensure social justice, equality and stable social operation; realize economic interest. These contents comply with basic standard of building a socialist country under the rule of law. But in order to realize sustainable development, it is required to improve and perfect many aspects for socialist ecological civilization construction. Currently, Chinese government has proposed the call for ecological civilization construction. Current economic law cannot meet the needs of social and economic development. Thus, the shortcomings gradually appear. So, we must change traditional 
ideas, blend new development of sustainable development in the idea of economic law, regard comprehensive construction of socialist ecological civilization as the objective and advance jointly.

Firstly, rebuild legal justice concept. Traditional legal concept emphasizes justice among people is narrow. Economic law mainly adjusts economic relations of each economic entity during economic operation. The main adjustment contents include human economic activities. Under such legal system, stable economic operation can be ensured for contemporary people. But, it lacks generalized fairness thinking and fails to overall plan and consider sustainable development of human economy. Obviously, this does not comply with sustainable development idea required by national ecological civilization construction. In a bid to establish justice system for laws fundamentally, it is necessary to reshape justice idea under the theoretical direction of ecological civilization construction. Resource utilization and allocation should be confirmed according to ecological protection responsibilities people in different times can undertake. National government should establish and perfect long-term resource application plan, plan resource application as a whole according to total resource amount and economic development speed, enhance control and management with legal and administrative means and regard the process of realizing ecological fairness in economic law as the approach to realize substantial fairness.

Secondly, adjust the idea of economic security. Traditional idea of economic law security falls behind, which is mainly reflected in lacking open thinking mode, focusing on fixed industries in a period and in some regions. Certain achievements have been gained through enhancing management force. Such economic planning and management mode is dominated by management of main market players and their economic behaviors, without comprehensive consideration of environmental influences. So, when formulating economic plans, the government must attach importance to dealing with the relationship between human and nature, make overall arrangements of all regions and carry out scientific management with the vision of strategic development in the process of optimized resource allocation. It is required to strive to develop green industry, input funds to develop the circular economy, protect renewable resources, take full advantage of non-renewable resources and make long-term plans well. During legislation of economic law, it is required to guarantee these measures legally and regard establishment of circular economic law and green economic law as the main idea and the basis to guide the direction of economic development. Meanwhile, it is required to establish overall ecological view and enhance inter-regional harmonious development of economy. Such economic development mode can realize real economic security.

Thirdly, comprehensively assess economic benefit. Economic benefit is the goal of economic development. Under the guidance of such idea, people pay attention to production input and output, improve production enthusiasm and create certain productivity effect within a period. Under the theory of ecological civilization construction, production input cannot be increased unilaterally in order to pursue benefit. The benefit of ecological environment should be overall considered. Moreover, under present economic benefit checking mode, environmental cost is not regarded as a statistical index. Economic law fails to provide corresponding provisions. Main market players fail to consciously incorporate environmental cost in economic accounting. In this way, economic benefit accounting cannot comprehensively reflect economic development quality.

Finally, establish scientific development perspective. The main purpose of traditional economic law is to accelerate economic development, while the theory of ecological civilization construction redefines the development. The key points are as follows: cognize the relation between human and nature again; ensure harmonious coexistence of human and nature; comprehensively improve economic development; find out the equilibrium point of economic development speed and environmental protection; change traditional mode of exchanging high consumption and heavy pollution for high-speed economic development; energetically develop green economy and circular economy; comprehensively consider bearing capacity of society, natural environment and resources in economic development process. 


\section{Reconstruction of the idea of China's economic law}

\section{To stick to people first and establish comprehensive ecological value idea}

In essence, ecological civilization construction is a part of transforming natural activities by human. The key to ecological civilization construction is to highlight the dominant position of human and give play to the effects of human. This is also the starting point of reconstruct economic law. To stick people first and realize harmonious development between human and nature is the best approach to guarantee all-round development of human society. Sharing economic development achievements is the development goal of socialistic China. Traditional economic law fails to fully cognize protection of ecological balance while ensuring stable operation and development of economy and leads to certain damage to environment in the process of rapid economic development. In current stage, people have realized the importance of protection of ecological environment. Rational utilization of resources, enhancement of environmental protection force and realization of development and protection balance are not just for protecting natural environment, but also for guaranteeing human living environment. It is required to stick to people first, take the way of sustainable development, regard human and nature as the subject of economy and make overall planning well. To give full play to and mobilize subjective initiative and enthusiasm of vast masses and to strengthen ecological civilization construction is the main objective of adjustment of economic law. Under the condition where human development and ecological protection contradict, scientific methods should be adopted to solve contradictions and find out the common point. It is required to scandalize market economic activities with laws, avoid the behaviors destroying natural environment for short-term economic interest and satisfy the needs of increasingly rising material culture and ecological environment.

\section{To establish management system for ecological civilization construction}

Order is one of important legal ideas. Economic law is also of no exception. Under order requirement of economic law, although freedom of market individuals receive due attention and market individuals enjoy full rights, basic environmental protection must be done well during formulating economic development plan. Management of ecological civilization society includes development of circular economy, intensive social construction and sustainable development policy. The functions are essential. Joint development must be ensured.

\section{Conclusions}

At present, China has explicitly put forward the struggling objective of ecological civilization construction. This is another great leap of socialist development after material civilization and spiritual civilization construction. It is an important strategy of Chinese government to promote long-term, stable and sustainable development of Chinese nation. Ecological civilization construction is an important constituent part of a harmonious socialist society with Chinese characteristics, new task and requirement of implementing scientific development perspective. The major approach to complete such great task is to rule by law and provide legal guarantee. It is required to take the following as the purpose of legislation and lead the whole society to form the idea of ecological civilization: establish new system of economic law, regard ecological civilization as the fundamental idea, enhance construction of circular economy and green economy, continuously strengthen sustainable development ability, protect ecological balance, optimize resource allocation, promote harmony between human and nature, promote the whole society to walk the development way of production development, rich life and good ecological civilization.

\section{References}

[1] Wan Weiwei, Wu Hua: Empirical analysis of synergic relationship between ecological civilization and economic and social development, Jiangxi Social Sciences, 2013(08) 
[2] Qiao Gang: Analysis of ecological civilization idea and new development way of circular economy, Environmental Pollution \& Control, 2010(05)

[3] Wu Hang: On ecological transformation of Chinese industry under ecological civilization perspective, Ecological Economy, 2009(10)

[4] Li Yuji: Ecological civilization: fundamental idea of Circular Economy Law, Journal of Gansu Political Science and Law Institute, 2008(03)

[5] Qiao Hailian: Enterprise environmental responsibility under Circular Economy Law, Environmental Protection and Circular Economy, 2010(30)

[6] Shi Wenya: Analysis of essential attribute of economic law, Journal of Xinxiang University(Social Sciences Edition), 2011(25)

[7] Zhang Linhong: Cheng Yingwei, Ccoordinated development of national and regional economy under economic law, Guizhou Social Sciences, 2008(09) 